\title{
RESPOSTA DE PLANTAS DE MILHO À SIMULAÇÃO DE DANOS MECÂNICOS
}

\author{
DÉCIO KARAM ${ }^{1}$, ISRAEL ALEXANDRE PEREIRA FILHO ${ }^{1}$, PAULO CÉSAR \\ MAGALHÃES ${ }^{1}$, MARIA CRISTINA DIAS PAES ${ }^{2}$, JÉSSICA ALINE ALVES SILVA ${ }^{3} \mathrm{e}$ \\ JORDÂNIA DE CARVALHO MACÊDO GAMA ${ }^{4}$
}

${ }^{1}$ Pesquisador da Embrapa Milho e Sorgo, Cx. Postal 151, CEP: 35701-970, Sete Lagoas, MG, E-mail:karam@cnpms.embrapa.br, israel@cnpms.embrapa.bre pcesar@cnpms.embrapa.br ${ }^{2}$ Doutora em Ciência de Alimentos, Embrapa Milho e Sorgo, E-mail: mcdpaes@cnpms. embrapa.br

${ }^{3}$ Graduanda em Engenharia Ambiental, UNIFEMM, Embrapa Milho e Sorgo, E-mail: jessicaalial@gmail.com

${ }^{4}$ Mestranda em Ciências Agrárias, UFMG,E-mail: jordaniama@gmail.com

$\overline{\text { Revista Brasileira de Milho e Sorgo, v.9, n.2, p.201-211, } 2010}$

RESUMO - O objetivo deste trabalho foi avaliar os efeitos do corte ou maceração simulados no milho sobre indicadores produtivos. Para tanto, um experimento foi instalado no campo experimental da Embrapa Milho e Sorgo, em Sete Lagoas, MG. Os tratamentos visaram reproduzir o corte ou a maceração da parte aérea das plantas, nos estádios de crescimentos V2 e V4. Avaliaram-se danos sobre a produtividade de grãos, biomassa seca acumulada da parte aérea (folhas, colmo, pendão e estilosestigmas), alturas de inserção de espigas e de plantas, relação massa de espigas/ massa total acumulada e índices de colheita. A biomassa do colmo do milho diferiu significativamente dos demais tratamentos no estádio V4. Entretanto, folhas, pendões e estilos-estigmas diferiram significativamente também em V4. Semelhança foi visualizada dentro dos tratamentos para a altura de inserção de espigas e plantas. A análise de produtividade de grãos revelou dissimilaridade entre tratamentos com danos simulados e testemunha. A relação massa de espigas/massa total e índice de colheita não foi diferente entre os tratamentos. As plantas submetidas ao corte e à maceração sofrem prejuízo no que tange à biomassa acumulada de elementos da parte aérea, em relação às plantas não-danificadas. Danos mecânicos causados no V4 da cultura são mais prejudiciais à produtividade de grãos do milho. Os danos ocasionados por corte ou maceração nos estádios V2 e V4 reduziram a produtividade de grãos.

Palavras-chave: Zea mays, cultivo múltiplo, partição de peso seco, estádios de desenvolvimento. 


\title{
RESPONSE OF MAIZE PLANTS TO SIMULATED MECHANICAL DAMAGES
}

\begin{abstract}
The aim of this work was to evaluate either incision or maceration simulated damage in maize. A field experiment was established at Embrapa Maize and Sorghun farm, Sete Lagoas, MG, Brazil. The treatments aimed to simulate cut and crush of the aerial parts of maize plants at V2 and V4 stages. Damages were assessed on grain yield, accumulated dry biomass of aerial parts (leaves, stalks, tassels and stylesstigmas), height of ear insertion, plant height, ear biomass/total biomass accumulated ratio and harvest indexes. Biomass of maize stalk in V4 was significantly different from other treatments. Leaves, tassels and styles-stigmas also significantly differed in V4. Similarity was seen within treatments for height of ear insertion and plant height. The analysis of grain yield revealed dissimilarity between treatments with simulated damage and control. Ear biomass/total biomass ratio and harvest indexes were not different among treatments. Plants submitted to cut and maceration showed decreased accumulated aerial biomass, compared to non-damaged plants. Mechanical damages at V4 stage are more detrimental to corn yield. The damage caused by cut or crush in V2 and V4 stages of maize reduced the grain yield.
\end{abstract}

Key words: Zea mays, multiple cropping, dry weight partitioning, growth stages

O milho é um dos cereais mais importantes do mundo, devido à sua vasta potencialidade de uso e boa responsividade ao implemento tecnológico. No Brasil, a ampla área cultivada com esse cereal, cerca de 14 milhões de hectares, e o montante produzido em 2009/2010 situaram o país na terceira posição mundial em área colhida (Storck et al., 2010). O sexto levantamento sobre grãos, "Acompanhamento da Safra Brasileira" (Conab, 2010a), relata a produção total do milho, $1^{\mathrm{a}}$ e $2^{\mathrm{a}}$ safras $09 / 10$, com rendimento de $51.383 \mathrm{t}$, ou seja, $0,7 \%$ maior que a produção do ano agrícola anterior.
Para a $1^{\text {a }}$ safra $2010 / 2011$, entretanto, houve um recuo produtivo de 4\% em relação a 2009/2010, o qual foi atrelado principalmente a intempéries climáticas (Conab, 2010b).

A demanda por tecnologias que melhorem as cadeias produtivas, bem como confiram excelência à produção agrícola, por meio da máxima produtividade, menor custo e conservação do ambiente, tem configurado desafios emergentes a estudiosos e agricultores. Para o sistema produtivo de milho, somente nos últimos dez anos, variadas foram as tecnologias desenvolvidas e consagradas com vistas à 
utilização da técnica de plantio de cultivos múltiplos ou sequenciados (Macedo et al., 2009).

A aplicação desses métodos, seja por meio de máquinas e equipamentos empregados ou sob condições ambientais não favoráveis, pode acarretar danos mecânicos tais como injúrias ou deformações das plantas de milho, gerando efeitos indesejáveis ao longo do desenvolvimento da cultura e refletindo na produtividade de grãos. Tais efeitos podem ser expressos ou ressaltados no agravamento de processos adversos, pelo aumento de sintomas de injúria e abertura de canais à entrada de organismos patogênicos (Soave \& Wetzel, 1987).

No que tange à estrutura foliar, os danos causados podem refletir negativamente no crescimento de toda a planta, uma vez que as folhas respondem pela principal fonte de fotoassimilados, que são os mais importantes órgãos fotossintetizantes do milho. A capacidade fotossintética das folhas, a área foliar ativa e a forma de distribuição dos produtos para os diversos órgãos que asseguram a permanência do aparato fotossintético são de grande relevância à produção (Magalhães \& Jones, 1990; Magalhães et al., 2002; Batistella et al., 2008). Altas produtividades têm sido proporcionadas pelo aumento da área foliar, alterações na relação fitomassa e órgãos reprodutivos e por outras alterações morfofisiológicas (Magalhães et al., 2002).

A área foliar está estreitamente ligada aos processos fisiológicos vitais da planta, tais como fotossíntese, respiração e transpiração (Mondo et al., 2009), e os danos causados às folhas incidem sobre a atividade fisiológica dessa cultura como um todo (Alvim et al., 2010). Altas produtividades foram relatadas como resultado do aumento da área foliar, alterações na relação fitomassa e órgãos reprodutivos e por outras alterações morfofisiológicas (Durães et al., 2005). A massa acumulada por grãos diminuiu tanto quanto se reduziu a área foliar ativa fisiologicamente, em milho danificado por geada (Ximenes, 2004). A remoção de 50\% do limbo foliar acima da espiga provocou uma redução de $17 \%$ na produção de grãos, quando comparada à da testemunha, sendo este considerado o tratamento mais prejudicial (Lima et al., 2010), ratificando os resultados de Hsu (1978), Britz (1982) e Sarca et al. (1987)

Desse modo, estudos que visem reproduzir os efeitos de danos mecânicos impostos à cultura do milho se fazem pertinentes. Em face de tais premissas, o presente trabalho teve por objetivo avaliar os efeitos da simulação de danos mecânicos nas folhas de plantas de milho sobre o acúmulo de biomassa seca aérea e atributos da produtividade de grãos.

O experimento foi instalado no campo experimental da Embrapa Milho e Sorgo, em Sete Lagoas, MG, no ano agrícola 2007/2008, em solo classificado como Latossolo Vermelhodistrófico (LVd), textura média argilosa. Semeouse o híbrido DOW 2A120 CL Clearfield, no dia 12 março de 2008, para se obter, na colheita, uma densidade de 55.000 plantas $\mathrm{ha}^{-1}$, utilizandose o espaçamento de $0,7 \mathrm{~m}$, com parcelas 
experimentais de $50,4 \mathrm{~m}^{2}$. A adubação de plantio foi de $300 \mathrm{~kg} \mathrm{ha}^{-1}$ da fórmula 8-28-16 + Zn e, em cobertura, no estádio de seis a sete folhas completamente desenvolvidas, foram utilizados $80 \mathrm{~kg} \mathrm{ha}^{-1}$ de nitrogênio.

$\mathrm{O}$ delineamento experimental adotado foi de blocos ao acaso, com quatro repetições, constituídas de tratamentos que simularam danos mecânicos, por meio de corte (C) ou maceração $(\mathrm{M})$ das folhas, nos estádios de crescimento V2 (duas folhas completamente desenvolvidas do milho) e V4 (quatro folhas completamente desenvolvidas do milho): corte em V2 (V2C), maceração em V2 (V2M), corte em V4 (V4C) e maceração em V4 (V4M). O corte transversal e o maceramento nos estádios de crescimento V2 e V4 foram realizados acima da segunda folha completamente desenvolvida, após 10 e 15 DAE (dias após a emergência), respectivamente (Figura 1).

Aos 30 DAE das plantas, foi realizada uma pulverização com o herbicida nicosulfuron, associado ao atrazine, nas doses de $32 \mathrm{~g} \mathrm{ha}^{-1} \mathrm{e}$ $1000 \mathrm{~g} \mathrm{ha}^{-1}$, respectivamente, para o controle de plantas daninhas. O acúmulo de biomassa seca para colmo, folha, pendão e estilo-estigma foi avaliado aos 56 DAE. Na colheita, foram realizadas avaliações da altura de inserção de espigas e planta e produtividade de grãos. O rendimento de grãos foi obtido por meio da quantificação de massa dos grãos produzidos em $14 \mathrm{~m}^{2}$ de área em cada parcela, corrigindose a umidade para 13\%. A partir desses dados, foi calculada a relação massa de espigas/massa total das plantas, dada pela biomassa acumulada pelas espigas produzidas sobre a biomassa total produzida pelas plantas. Determinou-se também o índice de colheita, dado pela razão entre peso de grãos e massa total acumulada pelas plantas, para cada tratamento.

Os resultados foram submetidos à análise de variância, seguidos pelo teste de Tukey, para comparação de médias a nível $5 \%$ de probabilidade, quando identificada significância para o teste de F. Para tanto, foi utilizado o software Systat 13.

Os resultados da análise de variância permitiram identificar existência de diferenças, aos 56 DAE, no acúmulo de biomassa seca das partes nas plantas de milho submetidas ou não aos danos mecânicos (Tabela 1). Observou-se que a biomassa seca do colmo diferiu significativamente nas plantas de milho submetidas ao corte no estádio de quatro folhas completamente desenvolvidas (tratamento V4C), em relação à testemunha e àquelas que sofreram maceração em igual estádio (V4M). Estas, por sua vez, não diferiram quanto à biomassa seca acumulada do colmo. Em V2, a análise estatística dos dados permitiu inferir semelhança entre os tratamentos com corte e maceração. A redução da biomassa seca acumulada por colmos foi relacionada à translocação de matéria para os grãos, num ensaio em que se procedeu a desfolha manual de plantas de milho (Allison \& Watson, 1966). Em ensaio acerca da biomassa seca produzida por plantas de milho submetidas à infestação 


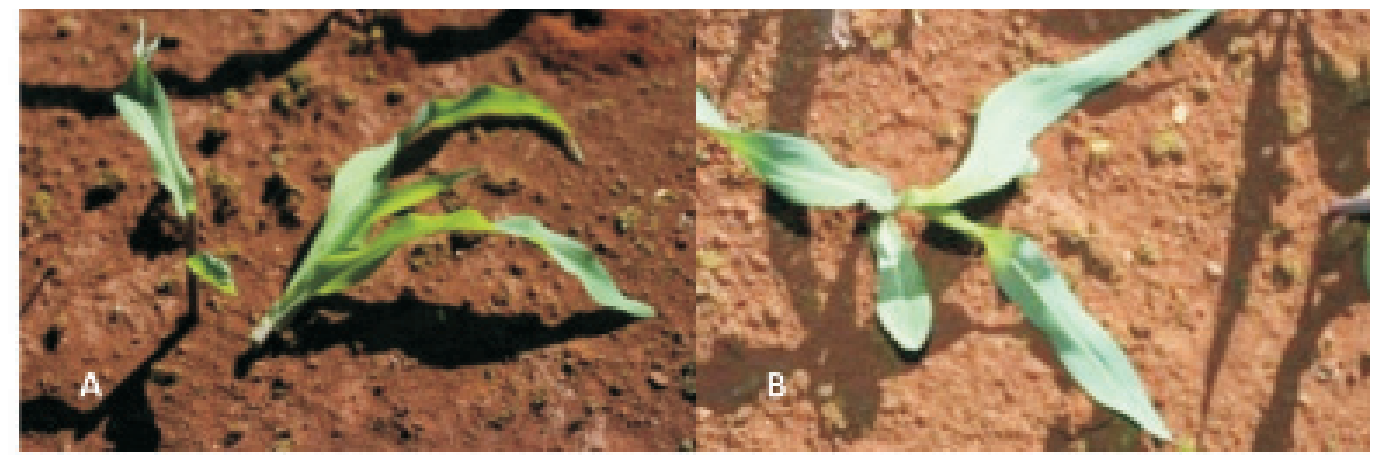

FIGURA 1. Aspecto de plantas de milho, aos 10 dias após a emergência, submetidas à simulação de danos mecânicos de folhas. Corte (A) e maceração (B). Sete Lagoas, MG, 2008.

de Dichelops melancathus (percevejo barrigaverde), no período V1 a V3, Roza-Gomes (2010) detectou a redução de 17,6\% da biomassa aérea acumulada, com base nos valores obtidos da testemunha, ainda que entre os tratamentos não tenha sido configurada diferença estatística.

$\mathrm{O}$ acúmulo de biomassa seca das folhas, pendões e estilos-estigmas foi afetado negativamente pelos danos mecânicos simulados em ambos os estádios e tratamentos, quando comparados à testemunha. $\mathrm{O}$ efeito do corte no estádio de quatro folhas foi o mais prejudicial ao acúmulo da biomassa seca para os componentes referidos, sendo o único estatisticamente diferente. Isso pode ser explicado pelo fato de que, nos estádios V4 e V5, ocorre a definição do potencial produtivo da planta (Magalhães et al., 2002). Lima et al. (2010) afirmam que o período crítico de perdas de folhas, para o milho, é próximo ao pendoamento, embora relatem a existência de resultados discordantes em função das variações da metodologia empregada e dos atributos genotípicos dos materiais avaliados. Barnnet \& Pearce (1983), apontaram a desfolha total ou parcial de plantas de milho como fator determinante na redução de biomassa acumulada dos elementos da parte aérea: colmos mais pendões, bainhas mais lâminas e inflorescências femininas.

Em relação à contribuição percentual dos elementos da parte aérea na biomassa acumulada total (Figura 2), pôde-se perceber, para o tratamento com o milho em V4, sob maceração, a segunda maior e a menor, respectivamente, participações dos colmos e folhas, comparadas às de todos os outros tratamentos, incluindo a testemunha. As porcentagens de participação na matéria seca dos tratamentos: corte em V2, maceração em V2, corte em V4, maceração em V4 e testemunha corresponderam a 5,3; 7,2; 5,8; 5,4 e $6,7 \%$, para os pendões, e 5,$4 ; 4,7 ; 4,4 ; 4,6$ 
TABELA 1. Acúmulo de biomassa seca aos $56 \mathrm{DAE}^{1}$, em partes das plantas de milho submetidas à simulação de danos mecânicos nos estádios de duas (V2) e quatro (V4) folhas, por meio do corte (C) ou maceração (M) das mesmas. Sete Lagoas, MG, 2008.

\begin{tabular}{lcccc}
\hline \multirow{2}{*}{$\begin{array}{c}\text { Simulação de } \\
\text { dano mecânico }\end{array}$} & \multicolumn{4}{c}{ Biomassa seca (g) ${ }^{\mathbf{2}}$} \\
\cline { 2 - 5 } & Colmo & Folha & Pendão & Estilo-Estigma \\
\hline V2C & $719,64 \mathrm{AB}$ & $524,98 \mathrm{~B}$ & $74,22 \mathrm{~B}$ & $74,36 \mathrm{AB}$ \\
V2M & $656,83 \mathrm{AB}$ & $506,28 \mathrm{~B}$ & $95,67 \mathrm{~B}$ & $62,34 \mathrm{~B}$ \\
V4C & $447,98 \mathrm{~B}$ & $366,90 \mathrm{C}$ & $52,27 \mathrm{C}$ & $40,34 \mathrm{C}$ \\
V4M & $1030,11 \mathrm{~A}$ & $551,17 \mathrm{~B}$ & $85,6 \mathrm{~B}$ & $76,59 \mathrm{AB}$ \\
Sem simulação & $1105,78 \mathrm{~A}$ & $687,61 \mathrm{~A}$ & $134,77 \mathrm{~A}$ & $85,21 \mathrm{~A}$ \\
\hline
\end{tabular}

${ }^{1}$ Dias após a emergência.

${ }^{2}$ Médias seguidas por mesma letra, na coluna, não diferem estatisticamente entre si a 5\% de probabilidade, pelo teste de Tukey.

e 4,2\% para os estilos-estigmas, nessa ordem, não apresentando grandes variações (Figura 2). Para os tratamentos na ordem supracitada, as folhas contribuíram com 37,7; 38,3; 40,4; 32,5 e $34,2 \%$ do total da biomassa seca acumulada. Collantes et al. (1998) relataram redução de concentração de substâncias de defesa na parte aérea do milho sob desfolha, constatando maior aporte de recursos para mecanismos de crescimento e desenvolvimento.

Para as variáveis altura de inserção de espigas, altura de plantas, peso de mil grãos e umidade, não houve diferenças entre os tratamentos ( $p>0.05)$ (Tabela 2). Entretanto, no parâmetro produtividade de grãos (Figura 3), as plantas submetidas ao corte ou a maceração apresentaram redução, quando comparadas às plantas sem simulação de danos. Tal fato pode ter sido resultado da menor fonte de fotoassimilados pela remoção das folhas, alterando, assim, a relação fonte/dreno, pelo não atendimento à demanda por drenos, do momento da simulação dos danos até o restabelecimento das plantas. A interpretação dos resultados sobre a produção de grãos concorda com os resultados obtidos por Silva (2001), simulando a desfolha artificial parcial $(50 \%)$, procedida transversal ou longitudinalmente no milho Centralmex em florescimento: o rendimento de grãos e seus principais componentes da 


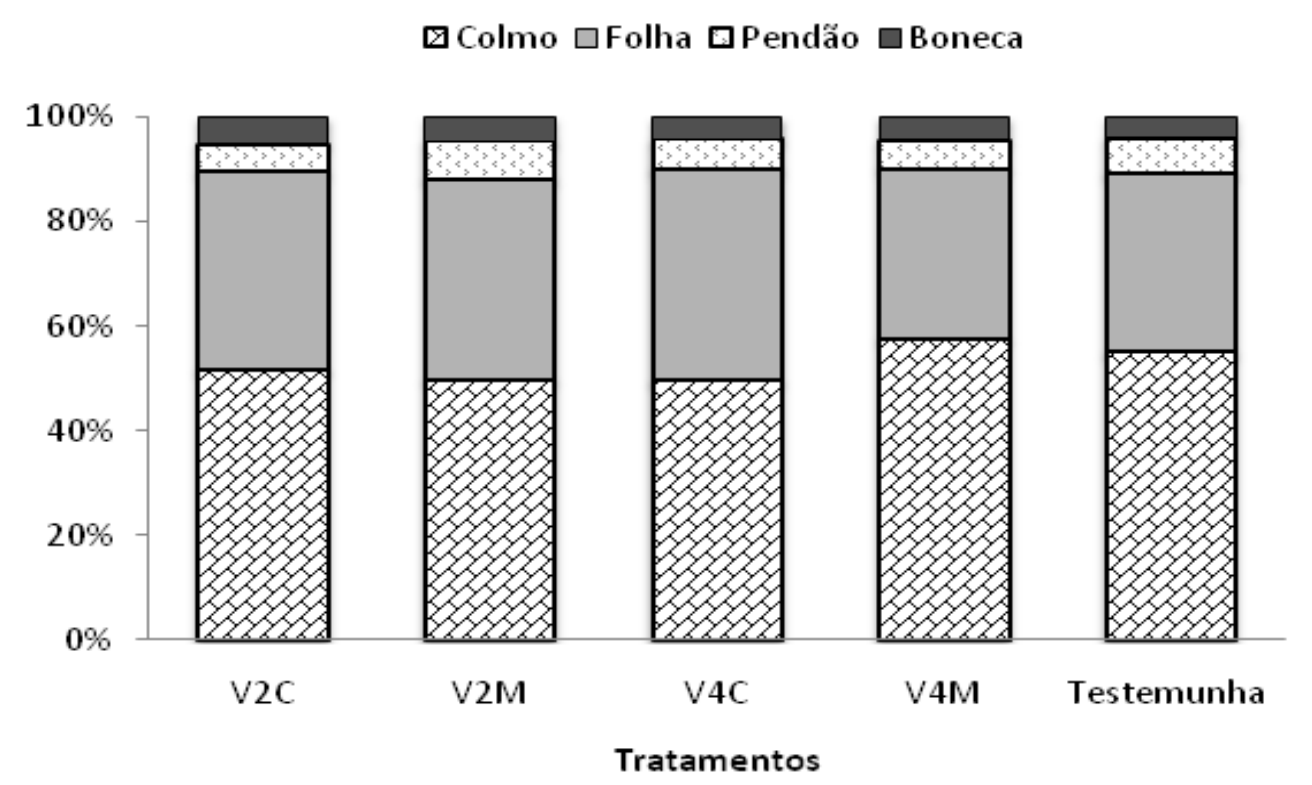

FIGURA 2. Percentagem de participação de matéria seca de colmos, folhas, pendões e estilo-estigmas na biomassa seca total de plantas de milho submetidas à simulação de danos mecânicos nos estádios de duas (V2) e quatro (V4) folhas verdadeiras, através do corte (C) ou maceração (M) das mesmas. Sete Lagoas, MG, 2008.

produção (relação espiga/planta, grãos/espiga e biomassa de 100 grãos) foi até $27,5 \%$ menor do que aquele verificado nas plantas não alvo de danos. Segundo Alvim et al. (2010), o efeito de redução da área foliar e desfolha do híbrido de milho NB7376 proporcionaram menor produtividade, em razão de $79 \%$ das folhas terem sido completamente removidas no estádio $\mathrm{R}$ da cultura, logo após a polinização das espigas. Ainda segundo esses autores, a menor disponibilidade de área foliar fisiologicamente ativa resultou em menor produtividade, o que pode também justificar a mesma ocorrência no presente estudo.

A simulação de danos não afetou significativamente a massa de espigas/massa total, sendo a média geral de 36,13\%, com mínima de 34,36 e máxima de 36,71\%. Em função da similaridade verificada após o tratamento estatístico, os dados dessas variáveis não foram apresentados. Quanto ao índice de colheita, constatou-se não haver diferença estatística significativa entre tratamentos com e sem simulação de danos. A média entre tratamentos foi 52,65 , com menor e maior valor iguais a 49,52 e 53,67, respectivamente.

Segundo Mundstock \& Silva (1989), Sangoi et al. (2002), as variações observadas nos índices de colheita das cultivares de milho estão diretamente associadas à capacidade de cada genótipo de translocar fotoassimilados para 
TABELA 2. Altura da inserção de espigas, altura de plantas e produção de grãos na colheita de milho submetido à simulação de danos mecânicos nos estádios de duas (V2) e quatro (V4) folhas, através do corte (C) ou maceração (M) das plantas. Sete Lagoas, MG, 2008. ${ }^{1}$

\begin{tabular}{lcccc}
\hline $\begin{array}{c}\text { Simulação de dano } \\
\text { mecânico }\end{array}$ & $\begin{array}{c}\text { Altura de espiga } \\
(\mathbf{m})\end{array}$ & $\begin{array}{c}\text { Altura de planta } \\
(\mathbf{m})\end{array}$ & $\begin{array}{c}\text { Peso de 1000 } \\
\text { grãos (g) }\end{array}$ & Umidade $^{2}$ \\
\hline V2C & $1,02 \mathrm{~A}^{2}$ & $1,92 \mathrm{~A}$ & $202,6 \mathrm{~A}$ & $30,3 \mathrm{~A}$ \\
V2M & $1,03 \mathrm{~A}$ & $2,02 \mathrm{~A}$ & $216,2 \mathrm{~A}$ & $30,8 \mathrm{~A}$ \\
V4C & $0,99 \mathrm{~A}$ & $1,94 \mathrm{~A}$ & $208,5 \mathrm{~A}$ & $30,2 \mathrm{~A}$ \\
V4M & $0,97 \mathrm{~A}$ & $1,91 \mathrm{~A}$ & $216,2 \mathrm{~A}$ & $32,1 \mathrm{~A}$ \\
Sem simulação & $1,08 \mathrm{~A}$ & $2,04 \mathrm{~A}$ & $203,9 \mathrm{~A}$ & $29,4 \mathrm{~A}$ \\
\hline
\end{tabular}

${ }^{1}$ Médias seguidas pela mesma letra, na coluna, não diferem estatisticamente entre si a $5 \%$ de probabilidade, pelo teste de Tukey.

${ }^{2}$ Umidade de grãos no momento da colheita.

os grãos. Já Tollenaar et al. (1994), Fancelli \& Dourado Neto (2000) e Sangoi et al. (2002) asseguram que tal competência está intrínseca às diferenças da atividade fotossintética das folhas, na longevidade foliar, na capacidade de remobilização de reservas do colmo para os grãos, na demanda competitiva exercida por outras estruturas da planta na fase reprodutiva da cultura e na eficiência de dreno da espiga.

Os danos causados pelo corte e maceração em plantas de milho nos estádios de crescimento V2 e V4 afetam o acúmulo de biomassa de folhas, colmos, pendões e estilo-estigmas, especialmente no estádio fenológico em que aquelas estão com quatro folhas completamente desenvolvidas.

Os danos simulados no milho em igual estádio não prejudicam a altura das plantas e a altura de inserção de espigas.

A relação massa de espigas/massa total não é afetada pelos danos simulados no milho, em V2 e V4.

Os danos mecânicos do corte transversal em V4 da cultura são mais prejudiciais à produtividade de grãos do milho.

Os danos ocasionados por corte ou maceração nos estádios V2 e V4 do milho reduziram o rendimento de grãos.

\section{Literatura Citada}

ALlisON, J. C. S.; WATSON, D. J. The production and distribution of dry matter in maize after flowering. Annals of Botany, London, v. 30, n. 119, p. 366-381, 1966.

ALVIM, K. R. T.; BRITO, C. H.; BRANDÃO, A. M.; GOMES, L. S.; LOPES, M. T. G. Quantificação da área foliar e efeito da desfolha em componentes de produção de milho. Ciência 


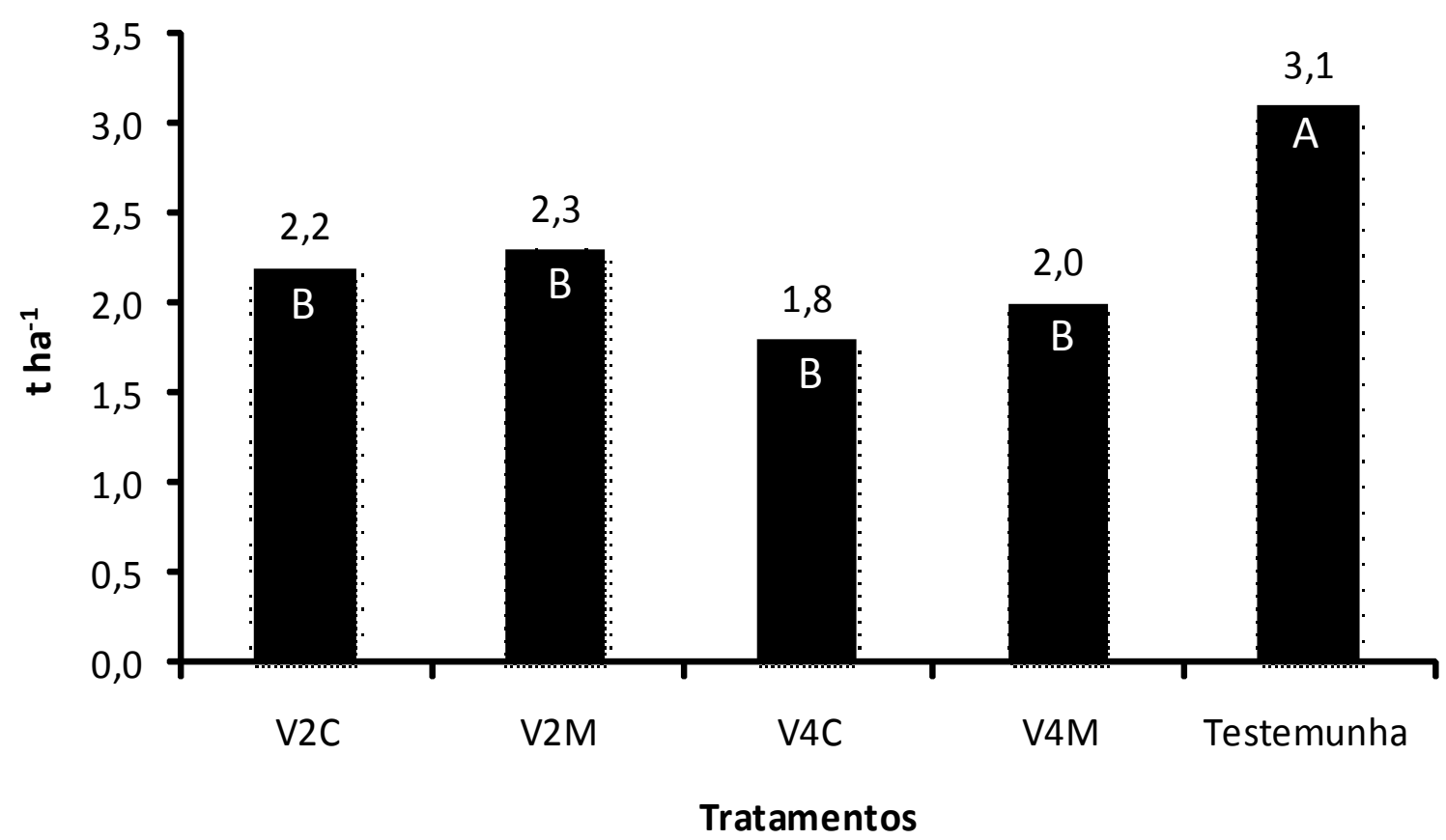

FIGURA 3. Produção de grãos de milho submetido à simulação de danos mecânicos nos estádios de duas (V2) e quatro (V4) folhas, por corte (C) ou maceração (M) da parte aérea. Sete Lagoas, MG. 2008. Médias seguidas pela mesma letra na barra não diferem estatisticamente entre si, a 5\% de probabilidade, pelo teste de Tukey. Sete Lagoas, MG, 2008.

Rural, Santa Maria, v. 4, n. 5, p. 1017-1022, 2010.

BARNETT, K. H.; PEARCE, R. B. Source sink ratio alteration and its effect on physiological parameters in maize. Crop Science, Madison, v. 23, n. 2, p. 294-299, 1983.

BATISTELLA, R. A.; SILVEIRA, D. L.; ALVIM, K. R. T.; BRITO, C. H. de; GOMES, L. S.; BRANDÃO, A. M. Determinação da Área Foliar de um Híbrido de Milho Com Alto Potencial Produtivo. In: CONGRESSO
NACIONAL DE MILHO E SORGO, 27.; SIMPÓSIO BRASILEIRO SOBRE A LAGARTA-DO-CARTUCHO, SPODOPTERA FRUGIPERDA， 3.; WORKSHOP SOBRE MANEJO E ETIOLOGIA DA MANCHA BRANCA DO MILHO, 2008, Londrina. Agroenergia, producao de alimentos e mudanças climáticas: desafios para milho e sorgo - trabalhos e palestras. [Londrina]: IAPAR; [Sete Lagoas]: Embrapa Milho e Sorgo, 2008.

COLLANTES, H. G.; GIANOLI, E.; NIEMEYER, H. M. Changes in growth and 
chemical defences upon defoliation in maize. Phytochemistry, New York, v. 49, p. 19211923, 1998.

\section{COMPANHIA NACIONAL DE} ABASTECIMENTO. Acompanhamento da safra brasileira: grãos - safra 2009/2010: quarto levantamento: janeiro/2010. [Brasília, DF]: CONAB, 2010. Disponível em < http:// www.conab.gov.br/conabweb/download/ safra/3graos_09.12.pdf.>.Acesso em: 30 nov. 2010a.

\section{COMPANHIA NACIONAL DE} ABASTECIMENTO. Acompanhamento da safra brasileira: grãos - safra 2010/2011: terceiro levantamento: dezembro/2010. [Brasília, DF]Ç CONAB, 2010. Disponível em < http://www.conab.gov.br/OlalaCMS/ uploads/arquivos/10_12_09_16_39_39_ boletim_portugues_-dez_de_2010..pdf.>. Acesso em: 02 dez. 2010 b.

BRITZ, G. D. The effect of defoliation at various growth stages on maize grain yield. Crop Production, Washington, v. 11, p. 8589, 1982.

FANCELLI, A. L.; DOURADO-NETO, D. Produção de milho. Guaíba: Agropecuária, 2000. 360 p.

HSU, F. H. Study on the effects of early defoliation on the agronomic traits of maize
(Zea mays L.) under different plant population densities. Journal of the Taiwan Livestock Research, Taiwan, v.11, p.63-71, 1978.

LIMA, T. G.; PINHO, R. G. V.; PEREIRA, J. L. A. R.;BRITO,A.H.;PINHO, E. V.R. V. consequências da remoção do limbo foliar em diferentes estádios reprodutivos da cultura do milho em duas épocas de semeadura. Bragantia, Brasília, DF, v. 69, n. 3, p. 563-570, 2010.

MACEDO, M. C. M. Integração lavoura e pecuária: o estado da arte e inovações tecnológicas. Revista Brasileira de Zootecnia, Viçosa, v. 38, p. 133-146, 2009. Suplemento especial.

MAGAlHÃES, P. C.; JONES, R. Aumento de fotoassimilados na taxa de crescimento e peso final dos grãos de milho. Pesquisa Agropecuária Brasileira, Brasília, DF, v. 25, n. 12, p. 1747-1754, 1990.

MAGAlHÃES，P. C.; DURÃES，F. O. M.; CARNEIRO, N. P.; PAIVA, E. Fisiologia do milho. Sete Lagoas: EMBRAPA-CNPMS, 2002. 23 p. (EMBRAPA-CNPMS. Circular Técnica, 22).

MONDO, V. H. V.; CARVALHO, S. J. P.; DOURADO NETO, D.; CICERO, S. M. Comparação de métodos para estimativa de área foliar em plantas de milho. Revista Brasileira de Milho e Sorgo, Sete Lagoas, v. 8, n. 3, p. 
233-246, 2009.

MUNDSTOCK, C. M.; SILVA, P. R. F. da. Manejo da cultura do milho. Porto Alegre: UFRGS, 1989. 76 p.

ROZA-GOMES, M. F. Avaliação de danos de quatro espécies de percevejos (Heteroptera: pentatomidae) em trigo, soja e milho. UPF, 2010, 105 f. Tese (Doutorado ) - Universidade de Passo Fundo, Passo fundo.

SANGOI, L.; LECH, V. A.; RAMPAZZO, C.; GRACIETTI, L. C. Acúmulo de matéria seca em híbridos de milho sob diferentes relações entre fonte e dreno. Pesquisa Agropecuária Brasileira, DF, v. 37, n. 3, p. 259-267, 2002.

SARCA, V.; BARBU, V.; DRAGOMIR, G. The effect of different emasculation methods on yield and biological purity of hybrids grains of maize. Seed Abstracts, Slough, v. 10, p. 292, 1987.

SILVA, P. S. L. Desfolha e supressão da frutificação em milho. Revista Ceres, Viçosa, MG, v.48, p.55-70, 2001.
SOAVE, J.; WetZEL, M. M. V. Patologia de sementes. Campinas: Fundação Cargill, 1987. $480 \mathrm{p}$.

STORCK, L.; CARGNELUTTI FILHO, A.; LOPES, S. J.; TOEBE, M.; SILVEIRA, T. R. Duração do subperíodo semeaduraflorescimento, crescimento e produtividade de grãos de milho em condições climáticas contrastantes. Revista Brasileira de Milho e Sorgo, Sete Lagoas, v. 8, n. 1, p. 27-39, 2010 .

TOLLENAAR, M.; NISSANKA, S. P.; AGUILERA, A.; WEISE, S. F.; SWANTON, C. J. Effect of weed interference and soil nitrogen on four maize hybrids. Agronomy Journal, Madison, v. 86, p. 596-601, 1994.

XIMENES, A. C. A.; SOUZA, L. C. F.; ROBAINA, A. D.; GONÇALVES, M. C. Avaliação da incidência de geadas em componentes de produtividade do milho. Revista Brasileira de Milho e Sorgo, Sete Lagoas, v. 3, n. 2, p. 214-227, 2004. 
